\title{
ANALISIS SIFAT FISIK DAN MEKANIK PADUAN ALUMINIUM DENGAN VARIABEL SUHU CETAKAN LOGAM (DIES) 450 DAN 500 DERAJAT CELCIUS UNTUK MANUFAKTUR POROS BERULIR (SCREW)
}

\author{
Andika Wisnujati ${ }^{1}$, Chirtian Sepriansyah ${ }^{2}$ \\ Program Studi D3 Teknik Mesin, Universitas Muhammadiyah Yogyakarta \\ Jl. Brawijaya, Tamantirto, Kasihan, Bantul, Daerah Istimewa Yogyakarta \\ Email: andikawisnujati@umy.ac.id ${ }^{1}$, chirtiansepriansyah123@yahoo.com
}

\begin{abstract}
Abstrak
Aluminium merupakan logam ringan yang mempunyai sifat ketahanan korosi dan mampu alir yang baik sehingga banyak digunakan dalam aplikasi alat-alat rumah tangga, otomotif, maupun industri saat ini. Piston bekas digunakan untuk mendapatkan unsur Si yang cukup tinggi pada piston. Ilmu pengecoran logam terus berkembang dengan pesat dalam dunia industri. Berbagai macam metode pengecoran telah ditemukan dan disempurnakan, diantaranya centrifugal casting, investment casting, dan sand casting serta masih banyak lagi metode-metode lainnya. Pada penelitian ini paduan Aluminium akan dicor pada 3 jenis variasi suhu cetakan sehingga dengan perlakuan panas terhadap cetakan logam (dies) yaitu $450^{\circ} \mathrm{C}$ dan $500^{\circ} \mathrm{C}$ diharapkan mampu memperbaiki sifat getas yang ada pada Aluminium. Temperatur dari variasi pemanasan suhu cetakan logam (die casting) dapat mempengaruhi dari sifat mekanik atau nilai kekuatan tarik dari suatu bahan dalam pembebanan dan sifat fisik atau stuktur mikro pada paduan Aluminium hasil peleburan. Pada penelitian ini dilakukan pengujian tarik dimana hasil pengujian maksimun terjadi pada pemanasan suhu cetakan $450^{\circ} \mathrm{C}$ yang menghasilkan tegangan tarik maksimun rata-rata sebesar $774,74 \mathrm{~N} / \mathrm{mm}^{2}$. Pengujian struktur mikro dengan hasil metalografi diperoleh stuktur mikro silikon austenit yang berbentuk jarum dan silikon primer yang berbentuk partikel kecil yang akan meningkatkan ketahanan aus material.
\end{abstract}

Kata kunci : Aluminium, Cetakan logam (dies), Sifat Mekanik-Fisis, Paduan.

\section{PENDAHULUAN}

Pengecoran logam merupakan salah satu ilmu pengetahuan tertua yang dipelajari oleh umat manusia dalam industri manufaktur. Ilmu pengecoran logam terus berkembang dengan pesat dalam dunia industri. Berbagai macam metode pengecoran telah ditemukan dan disempurnakan, diantaranya centrifugal casting, investment casting, dan sand casting serta masih banyak lagi metodemetode lainnya. Pengecoran adalah membuat kompenen dengan cara menuangkan bahan yang dicairkan ke dalam cetakan. Bahan ini dapat berupa metal maupun non-metal. Untuk mencairkan bahan diperlukan furnace (dapur). Furnace adalah sebuah dapur atau tempat yang dilengkapi dengan heater (pemanas). Bahan padat dicairkan sampai suhu titik cair dan dapat ditambahkan campuran bahan seperti Chrome, Silikon, Titanium, Aluminium dan lain-ain agar bahan menjadi lebih baik.

Aplikasi pengecoran sangat banyak salah satunya dalam pembuatan poros berulir (screw). Poros berulir ini terbuat dari logam Aluminium. Pengaplikasian poros berulir (screw) bisa digunakan industri rumahan maupun industri pabrikan. Seperti mesin pengupas kulit ari kedelai, pencacah sampah, dan lain sebagainya.

Adanya pengecoran poros berulir ini akan lebih memudahkan bagi para produsen rumahan dalam memproduksi suatu produk lebih higienis, mudah, dan 
cepat. Tujuan penelitian ini adalah untuk mengetahui pengaruh proses pengecoran pada paduan Aluminium bekas dengan penambahan unsur Ti-B $0.5 \%$ dengan pemanasan suhu cetakan logam $450{ }^{\circ} \mathrm{C}$ dan $500^{\circ} \mathrm{C}$ terhadap sifat fisik dan mekanik. Selain itu juga untuk mengetahui pengaruh hasil pengecoran poros berulir dengan penambahan Ti-B $0.5 \%$.

\section{TINJAUAN TEORITIS}

Hasil penelitian Hafis dan Lalu Alpan pada tahun 2016 [1] yang menganalisa penambahan unsur Ti-B (Titanium-Boron) sebanyak 0,02\% pada paduan Aluminium $50 \%$ Al-50\% (Al-Si) menggunakan cetakan pasir sand casting pada dua jenis variasi pemanasan suhu cetakan yaitu $200^{\circ} \mathrm{C}$ dan $300^{\circ} \mathrm{C}$. Pengujian yang dilakukan untuk mengetahui sifatsifat mekanis dan fisis paduan Aluminium tersebut yaitu pengujian tarik Tensile Strength, Kekerasan Hardness, dan metalografi dengan mikroskop optik. Hasil pengujian maksimun terjadi pada bahan paduan Al-Si dengan penambahan Ti-B $0,02 \%$ dan dengan pemanasan suhu cetakan $200^{\circ} \mathrm{C}$ menghasilkan tegangan tarik maksimun sebesar $618,8 \mathrm{~N} / \mathrm{mm}^{2}$, sedangkan untuk pengujian kekerasan (Vickers Hardness Number) menghasilkan angka kekerasan sebesar $103 \mathrm{~kg} / \mathrm{mm}^{2}$, dan untuk hasil metalografi diperoleh data stuktur yang terbentuk adalah fase hypereutectic silikon yang membentuk fasa silikon primer. Fasa tersebut memberikan ketahanan aus yang tinggi.

Menurut Annas [2] pada penelitiannya pada tahun 2017 yang berjudul "Analisa Sifat Fisik Dan Mekanik Poros Berulir (Screw) Berbahan Dasar 40\% Aluminium Bekas Dan 60\% Piston Bekas Dengan Penambahan 2,5\% Ti-B" menunjukkan bahwa Penelitian ini menggunakan campuran aluminium profil $40 \%$ dan $60 \%$ piston bekas dengan penambahan unsur Ti-B (Titanium-Boron) sebanyak $2,5 \%$ sebagai penghalus butir. Cetakan yang digunakan adalah cetakan logam (die casting) dengan 3 (tiga) jenis variasi pemanasan suhu cetakan yaitu $200^{\circ} \mathrm{C}, 300^{\circ} \mathrm{C}$ dan $400^{\circ} \mathrm{C}$. Pengujian untuk mengetahui sifat-sifat fisis dan mekanis pada paduan aluminium tersebut adalah pengujian tarik, kekerasan, dan metalografi dengan mikroskop optik. Hasil pengujian maksimum terjadi pada spesimen dengan pemanasan suhu cetakan $200^{\circ} \mathrm{C}$ menghasilkan tegangan tarik maksimum sebesar 148,08 $\mathrm{MPa}$, sedangkan untuk pengujian kekerasan vickers menghasilkan angka rata-rata kekerasan sebesar 95,1 $\mathrm{kg} / \mathrm{mm}^{2}$. Dan untuk hasil metalografi diperoleh data struktur mikro bahwa dengan menggunakan variasi pemanasan suhu cetakan dapat mempengaruhi struktur mikro pada spesimen hasil pengecoran paduan aluminium dengan penambahan $\mathrm{Ti}$ B 2,5\%, adapun fasa yang paling merata pembentukannya pada semua spesimen adalah fasa Al [5].

Proses pengecoran adalah suatu proses pembuatan yang pada dasarnya merubah bentuk logam dengan cara mencairkan logam, kemudian dimasukkan ke dalarn suatu cetakan dengan dituang atau ditekan. Di dalam cetakan ini logarn cair akan membeku dan menyusut. Produk hasil pengecoran dapat langsung dipakai sebagai produk akhir. Akan tetapi kebanyakan masih memerlukan proses lanjut seperti proses pemotongan, penyambungan, pembubutan, atau perlakuan phisis atau proses penyelesaian lain. Didasarkan di atas jenis bahan pola model cetakan dan cara penuangannya, maka proses peengecoran dapat dibedakan:

1. Proses pengecoran dengan pasir sebagai bahan cetakan (Sand casting),

2. Proses Pengecoran sentrifugal (Centrifugal Casting),

3. Dengan cetakan permanen (Permanent Mold Casting),

4. Cetak tekan (Die Casting),

5. Pola hilang (lnvesment Casting).

Suherman [3], pada tahun 2009 dalam penelitiannya yang menambahkan $\mathrm{Sr}$ atau TiB terhadap struktur mikro dan fluiditas pada paduan $\mathrm{Al}-6 \% \mathrm{Si}-0,7 \% \mathrm{Fe}$ didapatkan hasil bahwa penambahan 
elemen paduan seperti $\mathrm{Sr}$ atau $\mathrm{TiB}$ sangat signifikan mempengaruhi sifat fluiditas logam cair pada paduan $\mathrm{Al}-6 \% \mathrm{Si}-0,7 \% \mathrm{Fe}$, terutama pada rongga cetakan yang sangat tipis. Penambahan Sr kedalam paduan Al$6 \% \mathrm{Si}-0,7 \% \mathrm{Fe}$ cenderung menurunkan sifat fluiditas logam cair. Begitu juga dengan penambahan TiB pada paduan Al-6\%Si$0,7 \% \mathrm{Fe}$ sifat fluiditas logam cair menjadi berkurang.

Supriyadi [4], pada tahun 2011 menganalisa pengaruh variasi penambahan Ti-B pada bahan ADC 12 menggunakan proses pengecoran High Pressure Die Casting (HPDC) terhadap peningkatan kualitas bahan hasil coran sebagai bahan sepatu rem sepeda motor. Tahapan yang peneliti lakukan adalah pembuatan cetakan logam, merakit cetakan logam pada mesin HPDC, penyiapan material, peleburan, variasi penambahan Grain refiner Ti-B, $0,04 \%, \quad 0,08 \%, 0,12 \%, 0,16 \%, 0,2 \%$, $0,24 \%$, penuangan pada temperatur cetakan $200^{\circ} \mathrm{C}$, temperatur tuang $700^{\circ} \mathrm{C}$ dan tekan injeksi $7 \mathrm{MPa}$, pemeriksaan coran, analisa kekuatan coran dengan uji tarik dan kekerasan. Dari hasil pengamatan dan analisa pengujian didapatkan bahwa pada penambahan Ti-B $0,08 \%$ dihasilkan kekuatan tarik sebesar $300 \mathrm{~N} / \mathrm{mm}^{2}$ dan kekerasan 78,5 HRB hasil ini merupakan sifat mekanik yang paling baik dibandingkan apabila tidak mendapatkan penambahan inokulan Ti-B.

\section{METODE PENELITIAN}

Alat yang digunakan dalam proses penelitian ini meliputi timbangan digital, mesin uji tarik Servopulser dan mikroskop optik di Universitas Gadjah Mada.

Bahan-bahan yang digunakan pada penelitian ini antara lain:

\section{Aluminium bekas (AL-Si)}

Aluminium bekas yang digunakan adalah piston bekas yang didapat dari bengkel bengkel otomotif atau di barang rongsokan. Penggunaan Aluminium bekas di dalam penelitian seberat $4 \mathrm{~kg}$ atau 4000 gr dimana menyesuaikan ukuran cetakan logam. Aluminium dicairkan terlebih dahulu dan dicetak dalam cetakan pasir dengan bentuk bebas kemudian ditimbang dengan berat $4 \mathrm{~kg}$.

2. Titanium Boron (Ti-B)

Tambahan Titanium-Boron (Ti-B) berfungsi sebagai inokulan yaitu sebagai penghalus butir pada hasil peleburan. Titanium-Boron (Ti-B) ini memiliki harga yang mahal, dan penggunaannya untuk campuran peleburan tidak banyak, akan tetapi membutuhkan sedikit saja. TitaniumBoron yang digunakan dalam penelitian ini sebesar $0,5 \%$ atau 22 gram.

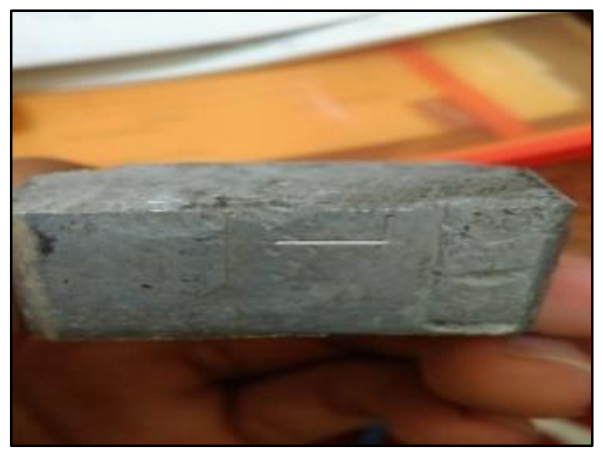

Gambar 1. Ti-B (Titanium-Boron)

Alasan penggunaan unsur tambahan Ti-B sebesar $0,5 \%$ adalah dikarenakan penambahan penghalus butir Ti-B pada paduan Al-Si dapat mempengaruhi bentuk pori, dimana pori tumbuh pada batas butir dan menghasilkan pori berbentuk bulat, sehingga bentuk permukaan jadi lebih halus karena ada penambahan Ti-B pada proses pengecoran.

Dalam penelitian ini dilakukan proses pengecoran Aluminium profil dan Aluminium dari piston berkas yang mengandung unsur silikon dengan penambahan unsur Ti-B sebagai penghalus butir. Pengamatan yang dilakukan adalah stuktur mikro dan sifat mekanik yang terjadi akibat dari variasi suhu cetakan $450^{\circ}$ $\mathrm{C}$, dan $500^{\circ} \mathrm{C}$.

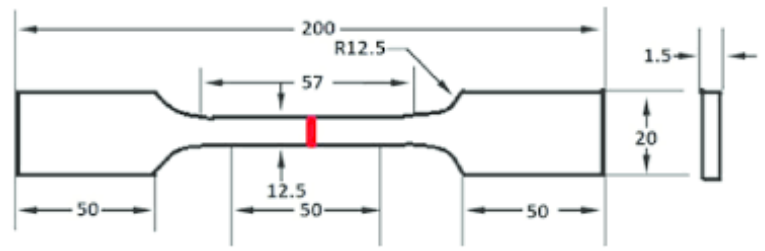

Gambar 2. Standar ASTM E8 
Spesimen yang disiapkan untuk pengujian berjumlah 8 sampel yaitu:

1. Pengujian tarik 6 spesimen 3 untuk hasil spesimen variasi suhu cetakan $450^{\circ} \mathrm{C}$ dan 3 hasil dari suhu cetakan spesimen $500^{\circ} \mathrm{C}$.

2. Pengujian stuktur mikro 2 spesimen 1 spesimen untuk $450^{\circ} \mathrm{C}$ dan 1 untuk $500^{\circ}$ C.

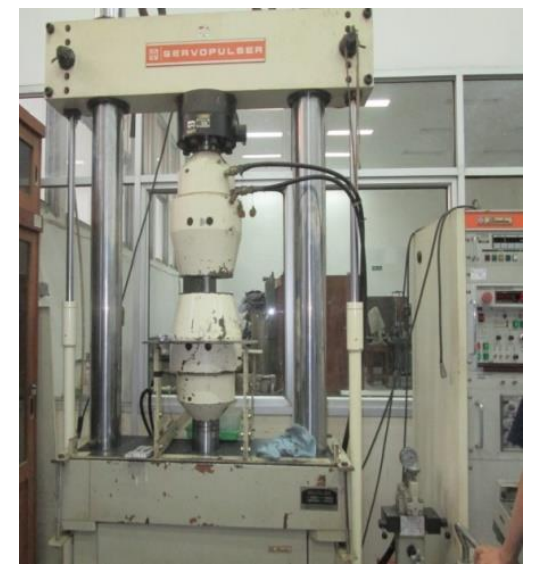

Gambar 3. Alat Pengujian Tarik

(Universal Testing Material)

Kekuatan tarik merupakan bahan untuk menerima beban tarik. Pengujian dialakukan dengan menggunakan mesin uji tarik, dengan cara menjepit sampel dengan kuat dan beban berikan secara kontinyu sampai sampel tersebut putus.

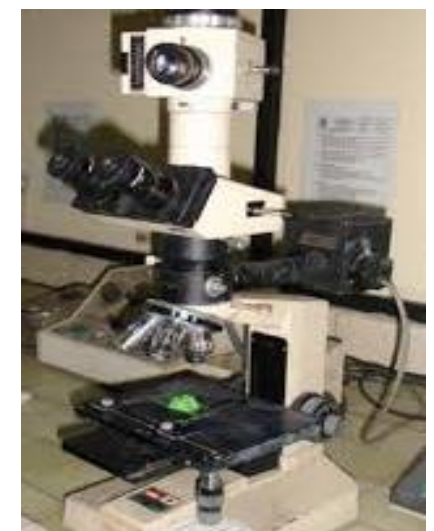

Gambar 4. Mikroskop Optik

(Metallurgical Microscope Invertgo Tipe)

Penyiapan spesimen untuk pengujian stuktur mikro sama dengan persiapan pengujian sebelumnya yaitu menyiapkan spesimen uji dengan cara memotong spesimen, karena spesimen adalah hasil dari cor-coran maka tidak perlu dibingkai dengan resin dan pemolesan dengan larutan kimia (etsa). Selanjutnya dilakukan pengamplasan sampai dengan permukaan spesimen uji terlihat bening seperti cermin.

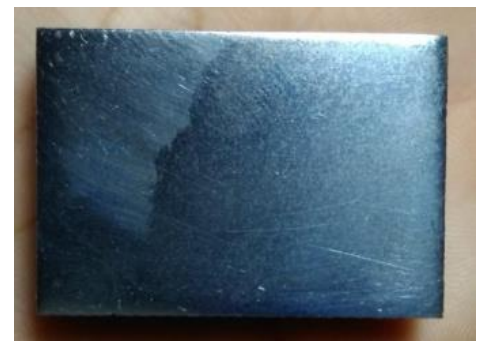

Gambar 5. Spesimen Uji Stuktur Mikro

Pengamatan perubahan struktur mikro akibat pengaruh variasi suhu cetakan diamati dengan pengujian metalografi yang dilakukan pada spesimen uji. Pengujian stuktur mikro ini bertujuan untuk mengamati stuktur mikro pada paduan Al$\mathrm{Si}+\mathrm{Ti}-\mathrm{B}$, terutama untuk mengamati perubahan stuktur mikro dari material yang diakibatkan dari proses peleburan dengan menggunakan variasi suhu cetakan.

\section{HASIL DAN PEMBAHASAN}

\section{Proses Pengecoran Logam}

Pembuatan spesimen dilakukan dengan proses pengecoran metode die casting atau menggunakan cetakan logam. Bahan yang digunakan adalah piston bekas (Al-Si) dengan penambahan unsur titanium boron (Ti-B). Proses pengecoran dilakukan dengan variasi suhu cetakan yaitu: $450{ }^{\circ} \mathrm{C}$ dan $500{ }^{\circ} \mathrm{C}$. Logam coran dalam proses pengecoran ini dilebur dalam tungku dengan bahan bakar gas. Tungku ini hanya mempunyai satu ruangan yaitu daerah kruss untuk mencairkan logam bahan tersebut.

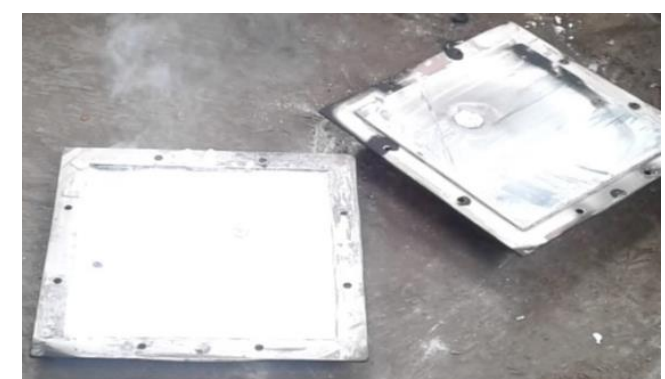

Gambar 6. Cetakan logam (Die Casting) 
Berikut merupakan tabel komposisi bahan peleburan yang digunakan dalam penelitian ini:

Tabel 1. Komposisi bahan baku peleburan

\begin{tabular}{|c|c|c|}
\hline \multirow{2}{*}{ Keterangan } & \multicolumn{2}{|c|}{$\begin{array}{c}\text { Komposisi Bahan } \\
\text { Pembuat Screw }\end{array}$} \\
\cline { 2 - 3 } & $\begin{array}{c}\text { Piston } \\
\text { bekas }\end{array}$ & Ti-B \\
\hline Gram & 4000 & 22,5 \\
\hline$\%$ & 100 & 0,05 \\
\hline
\end{tabular}

Mutu atau kualitas dari suatu produk pengecoran tergantung dari keadaan logam cair yang digunakan dalam proses pencetakan, karena semakin baik komposisi dari logam cair, semakin baik mutu atau kualitas dari hasil corannya. Semakin homogen logam cair, semakin baik pula hasil corannya.

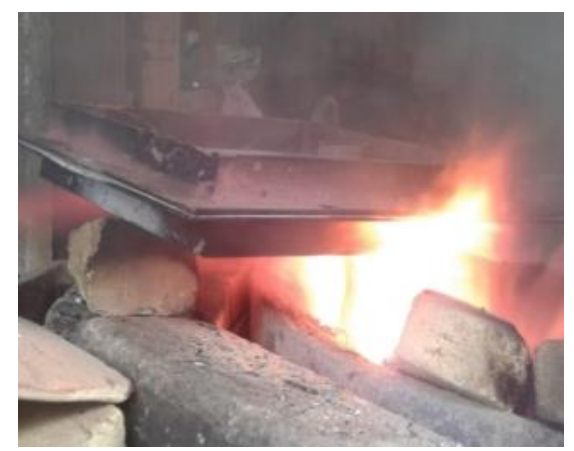

Gambar 7. Proses Peleburan Logam

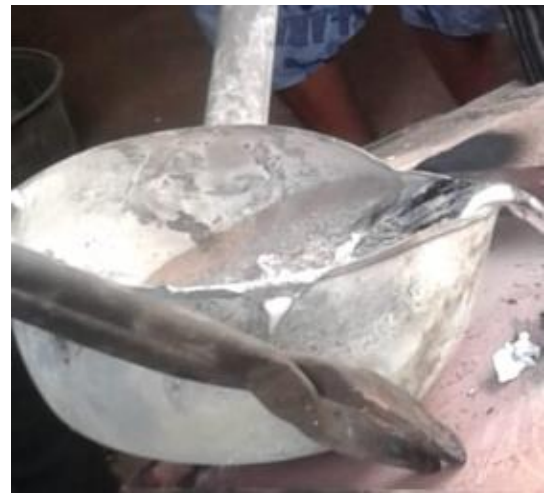

Gambar 8. Proses Penuangan Logam Cair kedalam Cetakan

\section{Pengujian Stuktur Mikro}

Pengamatan stuktur mikro dimaksudkan untuk memperoleh gambaran stuktur mikro pada permukaan spesimen hasil pengecoran yang telah dibuat. Pekerjaan ini meliputi persiapan spesimen melalu tahap pemotongan, diresin ketika spesimen sangat kecil karena untuk pegangan saat pengambilan gambar, diamplas, kemudian dietsa sebelum bahan ditempatkan di bawah lensa obyektif mikroskop optik. Pengujian mikrosuktur ini dilakukan untuk Aluminium paduan dengan penambahan unsur penghalus butir Ti-B dengan variasi suhu cetakan yang berbeda yaitu $450^{\circ} \mathrm{C}$ dan $500^{\circ} \mathrm{C}$ dengan alat uji metallurgical microscope invertgo tipe.

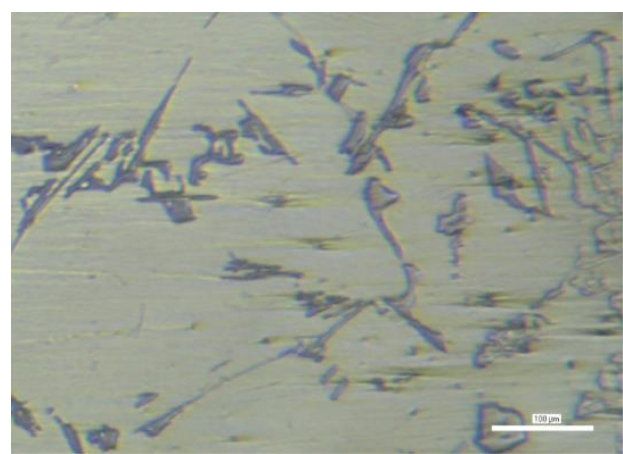

Gambar 11. Stuktur mikro spesimen Al-Si

+ Ti-B dengan variasi suhu cetakan logam $450^{\circ} \mathrm{C}$ dengan pembesaran $100 \mathrm{X}$.

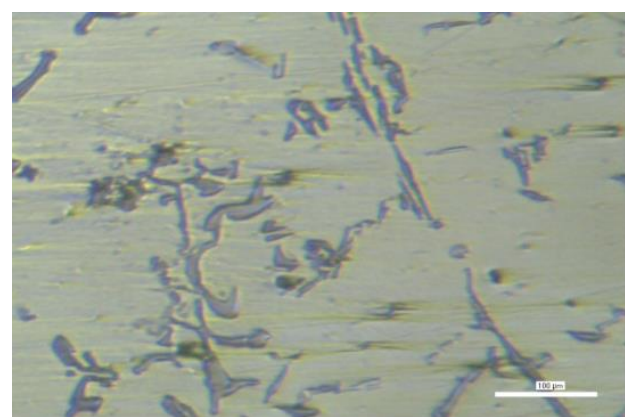

Gambar 12. Stuktur mikro spesimen Al-Si

+ Ti-B dengan variasi suhu cetakan logam $500^{\circ} \mathrm{C}$ dengan pembesaran $100 \mathrm{X}$.

Hasil pengamatan pada pengujian struktur mikro didapatkan bahwa terdapat partikel silikon yang berbentuk jarum dengan jenis struktur silikon eutektik dan silikon primer (coarse) yang berukuran kecil yang didapatkan karena paduan pengecoran aluminium, silikon dan Ti-B.

\section{Pengujian Tarik}

Pengujian tarik dilakukan di Laboratorium Bahan Teknik Departemen Teknik Mesin dan Industri, Universitas Gadjah Mada Yogyakarta. 


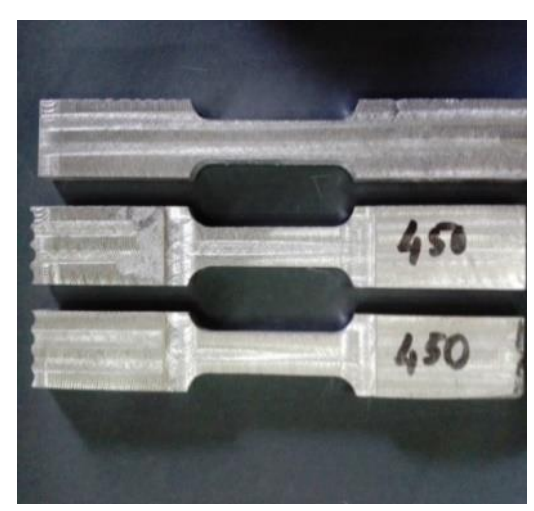

Gambar 9. Spesimen Uji Tarik

Pengujian tarik dilakukan untuk mengetahui kekuatan serta deformasi plastis yang terjadi pada spesimen paduan $\mathrm{Al}-\mathrm{Si}+\mathrm{Ti}-\mathrm{B}$ dengan variasi suhu cetakan sebesar $450^{\circ} \mathrm{C}$ dan $500^{\circ} \mathrm{C}$ untuk bahan pembuatan poros berulir (screw) dengan kapasitas maksimun 200 kN. Spesimen uji mengacu ASTM E8M, dengan alat uji Universal Testing Machine,

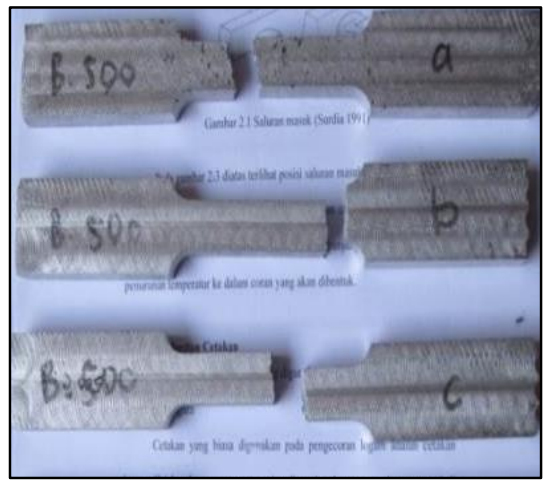

Gambar 10. Spesimen yang telah diuji

Tabel 2. Hasil Uji Tarik

\begin{tabular}{|c|l|l|l|l|}
\hline \multirow{3}{*}{ Suhu } & $\begin{array}{l}(\Delta \mathrm{L}) \\
(\mathrm{mm})\end{array}$ & $\begin{array}{l}\text { P.max } \\
(\mathrm{KN})\end{array}$ & $\begin{array}{l}\text { Reg. }(\varepsilon) \\
(\%)\end{array}$ & $\begin{array}{l}\text { Teg. } \\
(\sigma \mu) \\
(\mathrm{MPa})\end{array}$ \\
\hline \multirow{3}{*}{$450^{\circ}$} & 0,25 & 19,9 & 0.124 & 812,22 \\
\cline { 2 - 5 } & 0,05 & 21,9 & 0,024 & 989,70 \\
\cline { 2 - 5 } & 0,35 & 11.9 & 0,174 & 522,34 \\
\hline \multirow{3}{*}{$500^{\circ}$} & 0,4 & 5,3 & 0,204 & 233,33 \\
\cline { 2 - 5 } & 0,05 & 18,3 & 0,026 & 840,25 \\
\cline { 2 - 5 } & 0,35 & 10,4 & 0,184 & 476,08 \\
\hline
\end{tabular}

Setelah dilakukan pengujian tarik dari spesimen hasil pengujian tarik dapat diamati bahwa pada spesimen hasil peleburan coran logam dengan variasi suhu cetakan $450^{\circ} \mathrm{C}$ dan $500^{\circ} \mathrm{C}$ tersebut saat dilakukan pengujian tarik tidak terdapat pengecilan penampang sampai bahan spesimen tersebut putus atau patah, sifat mekanis logam yang demikian menunjukkan bahwa hasil coran tersebut tidak dapat dibentuk atau dideformasi plastis.

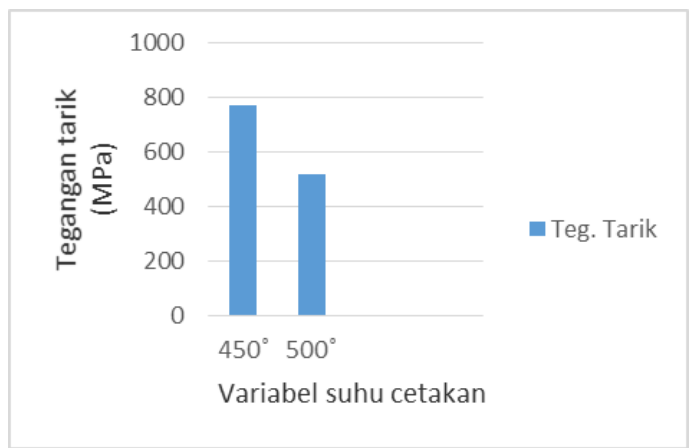

Gambar 11. Grafik Hasil Uji Tarik

Pada grafik hasil uji tarik di atas dapat dilihat bahwa nilai rata-rata kekuatan tarik pada variabel suhu cetakan $450^{\circ} \mathrm{C}$ sebesar 774,74 MPa dan pada variabel suhu cetakan logam $500^{\circ} \mathrm{C}$ sebesar 516,22 $\mathrm{MPa}$. Data uji tarik tersebut di atas didapatkan nilai tegangan tarik pada suhu cetakan logam $450^{\circ} \mathrm{C}$ lebih tinggi daripada tegangan tarik pada suhu cetakan logam $500^{\circ} \mathrm{C}$.

\section{KESIMPULAN}

Berdasarkan hasil studi literatur, penelitian, dan analisa serta pembahasan data yang telah dilakukan pada proses Analisis Sifat Fisik Dan Mekanik Paduan Aluminium Dengan Variabel Suhu Cetakan Logam (Dies) $450^{\circ} \mathrm{C}$ dan $500^{\circ} \mathrm{C}$ Untuk Manufaktur Poros Berulir (Screw), maka dapat diambil kesimpulan sebagai berikut:

1. Hasil tegangan maksimal pada pengujian tarik terjadi pada variabel pemanasan suhu cetakan logam $450^{\circ} \mathrm{C}$ dengan nilai tegangan rata-rata sebesar 774,74 MPa. Sedangkan pada pengujian struktur mikro diperoleh hasil berupa struktur mikro eutektik yang berbentuk jarum dengan komposisi silikon primer yang berbentuk partikel kecil.

2. Penambahan unsur titanium boron (TiB) sebanyak 0,5\% dapat mempengaruhi hasil coran sebagai penghalus butiran 
dan memberikan kekuatan tarik dari Bandung. paduan logam tersebut.

\section{REFERENSI}

[1]. Andika Wisnujati, Lalu Alpan Hafis, (2016), Analisis Sifat Fisik Dan Mekanik Porose Berulir (Screw) Untuk Pengupas Kulit Ari Kedelai Berbahan Dasar Aluminium Bekas Dan Piston Bekas. Yogyakarta: Jurnal Ilmiah, D3 Teknik Mesin Universitas Muhammadiyah Yogyakarta.

[2]. Annas, H.A. (2017), Analisa Sifat Fisik Dan Mekanik Poros Berulir (Screw) Berbahan Dasar $40 \%$ Aluminium Bekas Dan 60\% Piston Bekas Dengan Penambahan 2,5\% Ti-B.

[3]. Suherman, (2009), Pengaruh Penambahan $\mathrm{Sr}$ atau $\mathrm{TiB}$ Terhadap Struktur Mikro dan Fluiditas Pada Paduan Al-6\%Si-0,7\%Fe, Jurnal Dinamis Vol. II, No. 4, ISSN $0216-7492$

[4]. Supriyadi, A., Bayuseno, A.P dan Nugroho, S., (2011), "Pengaruh Penambahan Grain Refiner Ti-B Terhadap Bahan ADC12 Pada Pengecoran HPDC Untuk Peningkatan Kualitas Sepatu Rem Sepeda Motor Produk IKM", ORBITH Vol. 7 No. 3 November 2011: 393-400

[5]. Waluyo, dkk (2010) Pengaruh Temperatur Cetakan, Bentuk Produk Dan Inokulan Ti-B Pad Proses Pengecoran Sentrifugal Terhadap Sifat Fisis Dan Mekanis Paduan Aluminium. Jurnal Teknik Mesin, Politeknik Negeri 